\title{
Opioid-free anesthesia for a child with trisomy 13 with obstructive sleep apnea: a case report
}

\author{
Makiko Yamamoto* ${ }^{*}$, Izumi Miyazaki, Hiroaki Kishikawa and Atsuhiro Sakamoto
}

\begin{abstract}
Background: Most children with trisomy 13 display central apnea, and are prone to opioid-induced respiratory depression. We conducted opioid-free anesthesia for a patient with trisomy 13 and obstructive sleep apnea, and safely extubated the patient in the operating room.

Case presentation: A 27-month-old girl with trisomy 13 underwent tonsillectomy. Given her high sensitivity to opioids, general anesthesia was introduced and maintained only with 2-5\% sevoflurane and 33\% nitrous oxide in oxygen. We used acetaminophen for postoperative analgesia. The tracheal tube was removed under stable breathing pattern 10 min after the surgery in the operating room. Two years later, opioid-free anesthesia with 2-5\% sevoflurane and 33\% nitrous oxide in oxygen was again performed safely for tube insertion into both eardrums.

Conclusion: Opioid-free anesthesia with adequate non-narcotic analgesics is safe for children with trisomy 13 with multiple apnea-related comorbidities.
\end{abstract}

Keywords: Central apnea, General anesthesia, Non-narcotic, Obstructive sleep apnea, Opioid-induced respiratory depression, Opioid-free, Tonsillectomy, Trisomy 13

\section{Background}

Trisomy 13 is a chromosomal disorder resulting in an anatomically abnormal airway, central nervous system abnormalities that include respiratory depression, and congenital heart disease [1]. The incidence of this pathology is approximately 1 per 10,000 births, with a neonatal mortality rate of $75 \%$, and a 1 -year survival rate after birth as low as $10 \%$ [2-4]. Death is reportedly most often caused by lethal apnea, rather than heart failure [5].

Anatomically abnormal airways, such as cleft lip and palate, other facial deformities, laryngomalacia, and tracheobronchomalacia, can cause obstructive sleep apnea (OSA) [6]. On the other hand, the severity of central apnea is reportedly an important factor related to refractory apnea or lethal apnea $[7,8]$.

\footnotetext{
* Correspondence: m-yamamoto@nms.ac.jp

Department of Anesthesiology, Nippon Medical School, 1-1-5 Sendagi, Bunkyo-ku, Tokyo 113-8602, Japan
}

\section{Springer Open}

While opioids are included in postoperative analgesia for many surgeries requiring general anesthesia, opioidfree anesthesia can be performed to prevent adverse effects including opioid-induced respiratory depression. Risk predictors for opioid-induced respiratory depression include the 24-h period after surgery, airway surgeries, OSA, and developmental delay [9]. In such cases, non-narcotic analgesics may be a better option.

Because children with trisomy 13 have a frail central nervous system, they show heightened sensitivity to opioids. General anesthetic management for these individuals needs strategic consideration, especially for stabilization of the respiratory condition after the tracheal tube is extubated. Opioid-free anesthesia is one such strategy. A case of tonsillectomy for a girl with trisomy 13 with OSA resulting in chronic hypoxemia is reported. This case report is structured according to the CARE guideline [10].

(c) The Author(s). 2020 Open Access This article is licensed under a Creative Commons Attribution 4.0 International License which permits use, sharing, adaptation, distribution and reproduction in any medium or format, as long as you give appropriate credit to the original author(s) and the source, provide a link to the Creative Commons licence, and indicate if changes were made. The images or other third party material in this article are included in the article's Creative Commons licence, unless indicated otherwise in a credit line to the material. If material is not included in the article's Creative Commons licence and your intended use is not permitted by statutory regulation or exceeds the permitted use, you will need to obtain permission directly from the copyright holder. To view a copy of this licence, visit http://creativecommons.org/licenses/by/4.0/. 


\section{Case presentation}

A 27-month-old girl with trisomy 13 presented with OSA. She was born at 38 weeks' gestational age and hospitalized because of low birth weight. She was deaf and had been diagnosed with mosaic-type trisomy 13. Tracheomalacia and central apnea required ventilation support, but tracheomalacia had resolved 3 months after the birth with her growth, and central apnea had shown gradual improvement. She had been discharged without respiratory support at 8 months old. OSA had appeared at 2 years old due to increasing adenoid hypertrophy. Her parents reported snoring and apnea at night. She was on the monitor of peripheral oxygen saturation $\left(\mathrm{SpO}_{2}\right)$ at home, and home oxygen therapy started after identifying $\mathrm{SpO}_{2} \leq 80 \%$ on room air. Tonsillectomy under general anesthesia was scheduled for OSA and repeated otitis media.

At the time of hospitalization for surgery, her height was $76 \mathrm{~cm}$, and her weight was $10 \mathrm{~kg}$. Growth and development were equivalent to a child of about 18 months old. Preoperative chest X-ray and electrocardiogram examinations were normal. She had a patent ductus arteriosus that had been followed-up until this hospitalization. The latest transthoracic cardiac ultrasonography showed that the shunt flow was left-to-right, with a maximum velocity of $4.30 \mathrm{~m} / \mathrm{s}$, a maximum pressure gradient of $74.0 \mathrm{mmHg}$, and a pulmonary/systemic blood flow ratio of 1.1. Microcephaly and retrognathia were apparent (Fig. 1). Intermittent central apnea was present as one of the central nervous system complications of trisomy 13.

We did not provide her premedication before the induction of general anesthesia. General anesthesia was induced with sevoflurane up to $5 \%$ and $33 \%$ nitrous oxide in oxygen [11]. OSA made mask ventilation difficult even though two anesthesiologists were involved in positioning the head, moving the mandible forward, and opening the mouth to facilitate ventilation. She was placed in a lateral position and administered $100 \%$ oxygen immediately after $\mathrm{SpO}_{2}$ began to decrease. Spontaneous respiration resumed in the lateral position, and $\mathrm{SpO}_{2}$ improved. She became apneic intermittently with $100 \%$ oxygen and $5 \%$ sevoflurane, but assisted mask ventilation was easy in the lateral position. Then, we inserted a peripheral venous line. We administered 0.01 $\mathrm{mg} / \mathrm{kg}$ of atropine and $1 \mathrm{mg} / \mathrm{kg}$ of rocuronium intravenously. We performed tracheal intubation easily using a Macintosh-type laryngoscope. Two percent sevoflurane and 33\% nitrous oxide in oxygen remained throughout the rest of the case. Vital signs remained stable during the procedure without opioids and benzodiazepines. We administered $10 \mathrm{mg} / \mathrm{kg}$ of acetaminophen suppository for postoperative analgesia.

The operation took $36 \mathrm{~min}$, and spontaneous breathing resumed $10 \mathrm{~min}$ after discounting inhalational anesthetics. We administered $4 \mathrm{mg} / \mathrm{kg}$ of sugammadex sodium before extubation in the operating room. Her respiratory condition was monitored postoperatively in a high-care room with a stand-by ventilator for the rest of the day. It was because congenital central apnea due to trisomy 13 is prone to happen even with inhalational anesthetics. No apnea or desaturation was apparent. She was transferred to the general pediatric ward on postoperative day 2 and went home on postoperative day 4 . Radiographs confirmed that the nasopharyngeal airway was open following the tonsillectomy (Fig. 2). Home nasal oxygen was no longer needed postoperatively.

Two years later, we reapplied the same anesthetic protocol successfully during tube insertion into both eardrums for repeated otitis media. At this time, she had grown to $88 \mathrm{~cm}$ in height, and weight had increased to $13 \mathrm{~kg}$. Growth and development were equivalent to a child of about 30 months old. We did not provide her premedication. General anesthesia was introduced and maintained only with $2-5 \%$ sevoflurane and $33 \%$ nitrous oxide in oxygen. We initially tried to maintain her

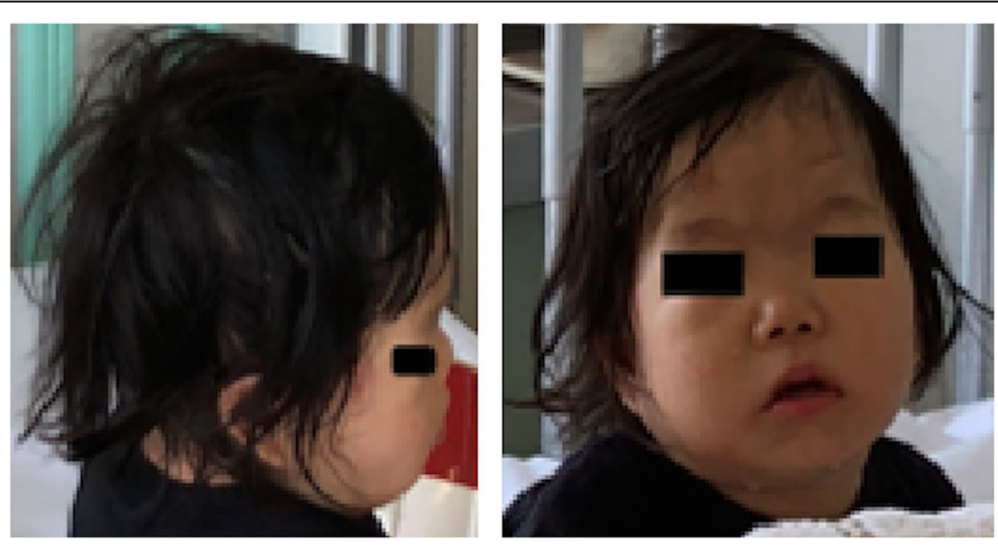

Fig. 1 Appearance of the head and neck. Pictures were taken during this hospitalization 


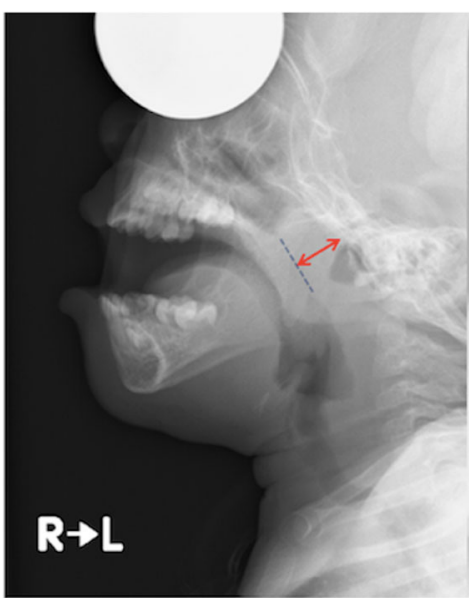

A) Pre-operative

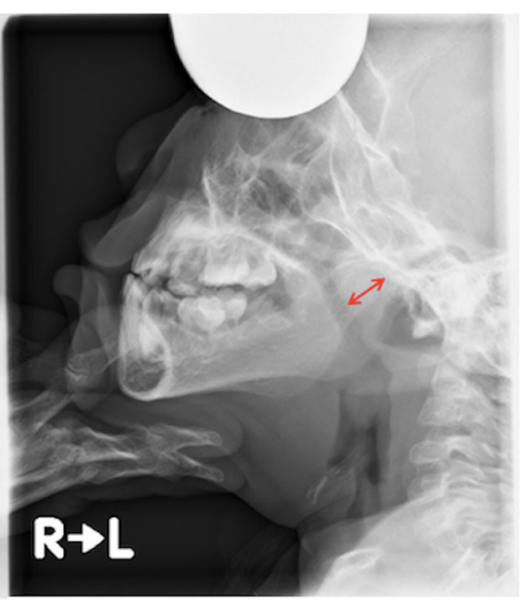

B) Post-operative

Fig. 2 Pre- and postoperative lateral-view radiographs of the nasopharynx. a Preoperative image. b Postoperative image. Bloated adenoids (a arrow) encroach on and severely obstruct the nasopharyngeal airway (a: dotted line). After tonsillectomy (b: arrow), the nasopharyngeal airway is open, allowing the patient to breathe with the mouth closed

spontaneous breathing effort during surgery. However, we noticed mild OSA and intermittent apnea. Therefore, we intubated the patient and controlled her ventilation, given the previous experience of easy tracheal intubation. The operation took $20 \mathrm{~min}$, and we extubated the patient under a stable breathing pattern in the operating room. The patient was fully awake and was, therefore, moved directly to a general pediatric ward with $\mathrm{SpO}_{2}$ monitor only at that time. No postoperative analgesics were needed.

\section{Discussion}

Opioid-free anesthesia was safely performed for tonsillectomy in a child with trisomy 13 who presented with OSA, which could cause opioid-induced respiratory depression. Adequate postoperative pain relief was achieved with an acetaminophen suppository. This strategy made the respiratory condition stable, allowed early withdrawal of ventilator support after the operation, and was reproducible.

Opioid-free anesthesia is thought to prevent postoperative central apnea resulting in delayed extubation or reintubation of a tracheal tube. Naloxone events caused by opioid-induced respiratory depression have been classified into six types, and precautions for each have been considered [9]. A reduction in opioid dose of at least $50 \%$ has been suggested for children with significant airway and apnea-related comorbidities, according to the reported classification [9]. This theory was applicable in the present case because of central apnea caused by trisomy 13.

OSA is also a special health condition requiring opioid dose reduction. Previous work has highlighted quantitative changes in opioid receptors in the brainstem that lead to increased sensitivity to opioids or benzodiazepines in children with chronic hypoxemia [12]. An anesthetic regimen for tonsillectomy in children has been presented, in which adjustments were made to the doses of midazolam and opioid depending on the severity of OSA [13]. Mask induction has been reported as safe with $30 \%$ nitrous oxide and sevoflurane up to $8 \%$ in oxygen, regardless of the severity of OSA. The patient in our case presented with OSA, which made mask ventilation difficult, but this problem was resolved by placing the patient in a lateral position. An oral airway could have been effective. Although administration of a muscle relaxant was avoided in the reported regimen, rocuronium was safely reversed with an adequate dose of sugammadex sodium.

The patient in this case presented with one of the most severe chromosomal triplication diseases with central apnea, in addition to OSA, with $\mathrm{SpO}_{2}$ reduced to approximately $80 \%$ in room air. The risk in the present case could have been higher than in other cases referred to when considering the prescribed strategies for opioidinduced respiratory depression [9]. Opioid analgesics needed to be replaced by non-narcotic analgesics as much as possible and the respiratory condition needed postoperative monitoring in the present case [9]. Opioid-free anesthetic management that focused on safe early extubation in the operating room for a child with trisomy 13 was reported for the first time.

One limitation in the present case was the difficulty in accurately evaluating analgesia. The patient showed mental delay and was deaf. Insufficient pain relief may have caused unstable breathing, laryngeal spasm, or 
dangerous excitement. For sufficient multimodal analgesia, local anesthesia could have been added. Another limitation was that nitrous oxide should be avoided in some cases, including those with ileus, increased intraocular pressure, increased tympanic pressure, or brain surgery. Otitis media may have excessively increased tympanic pressure if the anesthetic time had been longer. Finally, remifentanil can be used for tracheal intubation and maintenance of general anesthesia, since remifentanil has a short context-sensitive half-time of a few minutes.

\section{Conclusion}

Opioid-free anesthesia is appropriate for patients who have high sensitivity to opioids. Opioid-free anesthesia that provides sufficient pain relief can be performed with multimodal analgesics in children with trisomy 13 and OSA, which causes chronic hypoxemia, or any other apnea-related comorbidities.

\section{Abbreviations}

OSA: Obstructive sleep apnea; $\mathrm{SpO}_{2}$ : Peripheral artery oxygen saturation

\section{Acknowledgements}

None

\section{Authors' contributions}

MY and IM wrote the manuscript and prepared the images. HK and AS revised the manuscript. All authors read and approved the final manuscript.

\section{Funding}

None

\section{Availability of data and materials}

Data sharing is not applicable to this article as no datasets were generated or analyzed during the present study.

Ethics approval and consent to participate

In our institution, publication of case reports is exempted from Ethics Committee approval.

\section{Consent for publication}

Written, informed consent was obtained from the parents of the minor patient for publication of this case report and accompanying images.

\section{Competing interests}

The authors declare that they have no competing interests.

Received: 3 March 2020 Accepted: 4 June 2020

Published online: 11 June 2020

\section{References}

1. Pachajoa H, Meza Escobar LE. Mosaic trisomy 13 and a sacral appendage. BMJ Case Rep. 2013;2013.

2. Staso P, Paitl S, Patel DR. An 8-week-old infant with trisomy 13: dilemmas for medical decision making. AME Case Rep. 2018;2:3.

3. Meyer RE, Liu G, Gilboa SM, Ethen MK, Aylsworth AS, Powell CM, et al. Survival of children with trisomy 13 and trisomy 18: a multi-state population-based study. Am J Med Genet A. 2016;170a:825-37.

4. Kosiv KA, Gossett JM, Bai S, Collins RT. Congenital heart surgery on inhospital mortality in trisomy 13 and 18. Pediatrics. 2017;140.

5. Wu J, Springett A, Morris JK. Survival of trisomy 18 (Edwards syndrome) and trisomy 13 (Patau Syndrome) in England and Wales: 2004-2011. Am J Med Genet A. 2013;161a:2512-8.
6. Fernandes MBL, Salgueiro A, Bighetti EJB, Trindade-Suedam IK, Trindade IEK. Symptoms of obstructive sleep apnea, nasal obstruction, and enuresis in children with nonsyndromic cleft lip and palate: a prevalence study. Cleft Palate Craniofac J. 2018:1055665618776074.

7. Kamal M, Varghese D, Bhagde J, Singariya G, Simon AM. Singh A: [Anesthesia in a child operated for cleft lip associated with Patau's syndrome]. Rev Bras Anestesiol. 2018;68:197-9.

8. Wyllie JP, Wright MJ, Burn J, Hunter S. Natural history of trisomy 13. Arch Dis Child. 1994:71:343-5.

9. Chidambaran V, Olbrecht V, Hossain M, Sadhasivam S, Rose J, Meyer MJ. Risk predictors of opioid-induced critical respiratory events in children: naloxone use as a quality measure of opioid safety. Pain Med. 2014;15:2139-49.

10. Riley DS, Barber MS, Kienle GS, Aronson JK, von Schoen-Angerer T, Tugwell $P$, et al.: CARE guidelines for case reports: explanation and elaboration document. J Clin Epidemiol. 2017 May 18. pii: S0895-4356(17)30037-9. doi: https://doi.org/10.1016/j.jclinepi.2017.04.026.

11. Tsukamoto M, Hitosugi T, Esaki K, Yokoyama T. The anesthetic management for a patient with trisomy 13. Anesth Prog. 2017;64(3):162-4.

12. Khetani JD, Madadi P, Sommer DD, Reddy D, Sistonen J, Ross CJ, et al. Apnea and oxygen desaturations in children treated with opioids after adenotonsillectomy for obstructive sleep apnea syndrome: a prospective pilot study. Paediatr Drugs. 2012:14:411-5.

13. Isaiah A, Pereira KD. Outcomes after adenotonsillectomy using a fixed anesthesia protocol in children with obstructive sleep apnea. Int J Pediatr Otorhinolaryngol. 2015;79:638-43.

\section{Publisher's Note}

Springer Nature remains neutral with regard to jurisdictional claims in published maps and institutional affiliations.

\section{Submit your manuscript to a SpringerOpen ${ }^{\odot}$ journal and benefit from:}

- Convenient online submission

- Rigorous peer review

- Open access: articles freely available online

High visibility within the field

- Retaining the copyright to your article

Submit your next manuscript at $\boldsymbol{\nabla}$ springeropen.com 